\title{
UM ESTUDO COMPARATIVO DOS MODELOS BOX-JENKINS E REDES NEURAIS ARTIFICIAIS NA PREVISÃO DE VAZÕES E PRECIPITAÇÕES PLUVIOMÉTRICAS DA BACIA ARAGUAIA, TOCANTINS, BRASIL
}

A COMPARATIVE STUDY OF BOX JENKINS MODELS AND ARTIFICIAL NEURAL NETWORKS IN FORECASTING PLUVIOMETRIC FLOWS AND PRECIPITATIONS OF ARAGUAIA-TOCANTINS BASIN/BRAZIL

\section{Camil Wadih Salame (1)}

Doutorando na Universidade

Federal do Pará (UFPA) -

Belém (PA), Brasil.

Joaquim Carlos

Barbosa Queiroz ()

Docente na UFPA-

Belém (PA), Brasil.

Everaldo Barreiros

de Souza (1)

Docente na UFPA -

Belém (PA), Brasil.

Valcïr João da

Cunha Farias (1)

Docente na UFPA-

Belém (PA), Brasil.

\section{Edson José Paulino da Rocha (1)}

Docente na UFPABelém (PA), Brasil.

\section{Helyelson Paredes Moura (1)}

Docente na Fundação Universidade Federal do Amapá -

Macapá (AP), Brasil.

\section{Endereço para correspondência: Joaquim Carlos Barbosa Queiroz- Travessa Antonio Baena, 915, ap. 604 - Marco - CEP: 66093-082 - Belém (PA), Brasil - E-mail: joaquimqz@gmail.com}

Recebido em: 21/02/2019

Aceito em: 01/08/2019

\section{RESUMO}

Estudar a variabilidade dos parâmetros hidroclimáticos locais em bacias hidrográficas é importante para melhorar o gerenciamento dos recursos hídricos. Para tal, foram utilizados o modelo estatístico baseado na metodologia BoxJenkins, adotado por muitas empresas na análise de séries temporais, inclusive todo o setor elétrico brasileiro, e a tecnologia de redes neurais, que se apresenta como poderosa ferramenta para previsões. Na comparação entre as duas técnicas, foram utilizadas observações de médias mensais de duas estações meteorológicas da Bacia Araguaia-Tocantins, Brasil, uma de vazões mensais $\left(\mathrm{m}^{3} / \mathrm{s}\right)$ e outra de precipitações pluviométricas mensais ( $\mathrm{mm}$ ), da Agência Nacional de Águas (ANA), com registros contínuos nos períodos de 1969 a 2017 e 1974 a 2017. As previsões foram testadas para 12 e 24 meses. Uma comparação entre os dois métodos, usando o teste de hipótese a partir de intervalos de confiança de $95 \%$, mostrou que não houve diferenças estatisticamente significativas nas previsões individuais tanto de precipitações pluviométricas como de vazões. Entretanto, o uso do root mean square error (RMSE) mostrou que o método de Box-Jenkins apresenta melhores resultados. A maior dificuldade nesse método é na construção do modelo, sobretudo em séries com alta variabilidade. $O$ método de redes neurais, em geral, consome mais tempo computacional em relação ao Box-Jenkins.

Palavras-chave: variáveis climáticas; previsões; séries temporais; perceptron multicamada; raiz do erro quadrático médio.

\section{ABSTRACT}

Studying the variability of local hydro-climatic parameters in river basins is important for the better management of water resources. In order to do so, we used two methods: Box-Jenkins methodology, adopted by many companies in the time series analysis, including the entire Brazilian electric sector, and the Neural Networks technology, which presents itself as a powerful tool for forecasting. Observations of monthly averages of two meteorological stations of the Araguaia-Tocantins basin (Brazil) were made for comparation purposes, one of monthly flows $\left(\mathrm{m}^{3} / \mathrm{s}\right)$ and one of monthly rainfall $(\mathrm{mm})$, of the National Waters Agency (Agência Nacional de Águas-ANA) with continuous records from 1969 to 2017 and 1974 to 2017. The forecasts were tested for twelve and twentyfour months. A comparison between the two methods using a hypothesis test from $95 \%$ confidence intervals, showed that there were no statistically significant differences between them in individual rainfall and flow forecasts. However, if the RMSE method is used, the Box-Jenkins method presented better results in the forecasts. The main difficulty in the Box-Jenkins method is the construction of the model, especially in high variability series. The method of Neural Networks, in general, consumes more computational time compared to the Box-Jenkins model.

Keywords: climatic variables; forecasts; temporal series; multilayer perceptron; root mean square error. 


\section{INTRODUÇÃO}

Estudos relacionados às variabilidades climáticas e hidrológicas são importantes para atender à crescente demanda pela melhoria da qualidade de vida das pessoas no que tange à geração de energia e uso de recursos hídricos, além das atividades agropecuárias, industriais, turísticas e outras. O conhecimento sobre o futuro comportamento do clima e da hidrologia de rios em uma região e a compreensão de modificações registradas no presente exigem estudos relacionados às alterações de parâmetros climáticos e hidrológicos ocorridos no passado (IPCC, 2014). Diversos estudos já foram feitos no Brasil sobre a situação climática, em que se mostrou a ocorrência de muitas alterações de acordo com a região política. Marengo, Tomasella e Nobre (2010) consideram que estudos sobre a variabilidade dos parâmetros climáticos locais em bacias hidrográficas são de extrema importância para analisar o comportamento dos vários sistemas hídricos ao longo dos anos. Isso permite a realização de previsões visando a um melhor planejamento dos recursos hídricos, como construções de reservatórios para abastecimento de cidades e para geração de energia elétrica, dentre outros. $O$ estudo dos impactos das mudanças climáticas nas vazões dos postos do setor elétrico brasileiro, utilizando seis modelos do Intergovernmental Panel on Climate Change - First Assessment Report (IPCC-AR5) para os cenários RCP4.5 e RCP8.5 no período de 2011 a 2098, realizado por Silveira et al. (2018), mostrou evidências de maior possibilidade de redução nas vazões anuais na maior parte do Brasil, exceto para a região sul, onde os modelos utilizados mostraram aumentos superiores a 5\% no período de 2040 a 2069. Lira e Cardoso (2018), com uso do método de Mann-Kendall, realizaram uma análise de tendência nas séries de vazões de rios, em escala anual e sazonal, cujos resultados apontam tendências positivas nas vazões anuais de $75 \%$ dos postos da Região Sul do Brasil e na faixa sul do sudeste; e tendências negativas anuais de $50 \%$ dos postos na faixa norte do Sudeste e no Nordeste e Norte do país.

Motivado por essas questões, o presente estudo apresenta os resultados de dois métodos utilizados em previsões de observações futuras de parâmetros climáticos que usam séries temporais. Foram selecionadas séries de precipitações pluviométricas e vazões na região da Bacia Hidrográfica do Araguaia-Tocantins, considerada hidrologicamente a maior bacia inteiramente em território brasileiro, sendo responsável por abastecer importantes cidades e por possuir um elevado potencial hidroenergético.

O método de Box-Jenkins (BJ) vem sendo aplicado com sucesso como técnica promissora para previsão climática (CHECHI \& SANCHES, 2013; LÚCIO et al., 2010). Esse método é adotado por muitas empresas na análise de séries temporais, inclusive por todo o setor elétrico brasileiro. De forma similar, várias topologias de redes neurais artificiais (RNA) vêm sendo aplicadas com êxito acentuado tanto em séries temporais dos setores da economia e financeiro (TEALAB; HEFNY; BADR, 2017) quanto em previsão climática (ABHISHEK et al., 2012). Métodos híbridos envolvendo o modelo autorregressivo integrado à média móvel (ARIMA) e RNA têm se mostrado uma maneira efetiva de melhorar a precisão alcançada por ambos os modelos aplicados separadamente (ZHANG, 2003; KHANDELWAL \& VERMA, 2015). Na literatura são encontrados vários métodos para previsão de séries temporais, dentre os quais destacam-se o BJ, representado pelos modelos conhecidos como ARIMA e RNA (CHECHI \& SANCHES, 2013; LÚCIO et al., 2010; CHOON \& CHUIN, 2008; KHANDELWAL \& VERMA, 2015; ZHANG, 2003; HO et al., 2002; SAFEE \& AHMAD, 2014; TEALAB; HEFNY; BADR, 2017; ABHISHEK et al., 2012).

Vários pesquisadores realizaram estudos comparativos entre os métodos de BJ e RNA e, dependendo das séries em estudo, as conclusões foram diferentes. $O$ trabalho apresentado por Ho et al. (2002) na previsão de séries temporais de falhas de compressor mostrou que o modelo ARIMA e redes neurais recorrentes apresentaram resultados superiores aos obtidos pela rede neural feedforward. Em séries temporais de índice climático, Safee e Ahmad (2014) concluíram que o modelo sazonal autorregressivo e médias móveis (seazonal autoregresisve integrates moving average - SARIMA) se mostrou mais adequado, no que tange ao erro quadrático médio, em relação à rede neural feedforward. Diferentemente, Choon e Chuin (2008), em previsão de dados de temperatura, concluíram que redes neurais mostraram performance melhor quando comparadas ao método de BJ.

$\mathrm{Na}$ comparação entre esses dois métodos, pode-se destacar que, para a aplicação de séries temporais é necessário que sejam satisfeitas condições de estacionariedade, sazonalidade e número de dados 
(tamanho da amostra), limitações ausentes em modelos de RNA. O uso de séries temporais em processos não lineares apresenta um considerável grau de dificuldade, enquanto as RNA são notoriamente aceitas como métodos para aplicação em modelos não lineares. Entretanto, em RNA alguns parâmetros, tais como taxa de aprendizagem e número de neurônios em cada camada da rede, para uma maior precisão e confiabilidade da resposta, são determinados por tentativa e erro. Além disso, os pesos sinápticos são determinados por meio de um processo de otimização, o que pode consumir tempo para a obtenção do resultado final.
Para os modelos de séries temporais, os parâmetros são estimados por meio da função de máxima verossimilhança, o que é menos custoso quando comparado às RNA (CHOON \& CHUIN, 2008; SAFEE \& AHMAD, 2014; HO et al., 2002).

Em função das divergências de eficácia dos modelos de previsão, este trabalho aplicou o método de $\mathrm{BJ}$ e redes neurais feedforward para a previsão de dados futuros em séries temporais de vazão e precipitação pluviométrica obtidas na região centro-oeste do Brasil e, a partir disso, realizou uma comparação da eficácia de tais metodologias sobre esses dados.

\section{MATERIAIS E MÉTODOS}

\section{Área de estudo e dados usados}

A região hidrográfica do Araguaia-Tocantins possui uma área de $921.921 \mathrm{~km}^{2}$, equivalendo a $10,8 \%$ do território brasileiro. De acordo com o Instituto Brasileiro de Geografia e Estatística (IBGE, 2010), em 2010 a referida região apresentava população de 8.610 .721 habitantes, sendo $76 \%$ ocupando áreas urbanas, caracterizando densidade demográfica de $9,3 \mathrm{hab} . / \mathrm{km}^{2}$, portanto, inferior à do país, que era de $22,4 \mathrm{hab} . / \mathrm{km}^{2}$. O clima da região hidrográfica do Tocantins-Araguaia é tropical, com temperatura média anual de $26^{\circ} \mathrm{C}$, e dois períodos climáticos bem definidos: o chuvoso, de outubro a abril, com mais de $90 \%$ da precipitação, com a existência de alguns dias secos entre janeiro e fevereiro, formando o chamado veranico; e o seco, de maio a setembro, com baixa umidade relativa do ar. Os solos são geralmente profundos e bem drenados, como os

\section{Imputação múltipla}

A técnica da imputação múltipla (NUNES; KLÜCK; FACHEL, 2009; CAMARGOS et al., 2011) foi utilizada para a estimativa de valores faltantes observados nas duas séries. As séries foram divididas em duas partes: uma para o conjunto de treinamento e outra para o teste de validação

\section{Modelo Box-Jenkins}

De acordo com Morettin e Toloi (2006), uma série temporal (ST) pode ser definida como um conjunto de observações $Y_{t}$ em função do tempo. As principais ferramentas utilizadas para a análise de ST são: as fun-
Latossolos e Neossolos Quartzarênicos, com baixa fertilidade natural e boas características físicas, geralmente em relevo plano a suavemente ondulado (ANA, 2005). A Figura 1 mostra a área de estudo e as duas estações com dados mensais utilizadas neste estudo. Foram utilizadas observações de médias mensais de duas estações da Bacia do Araguaia-Tocantins, Brasil, uma de vazões mensais $\left(\mathrm{m}^{3} / \mathrm{s}\right.$ ) e outra de precipitações pluviométricas mensais $(\mathrm{mm})$, da Agência Nacional de Águas (ANA), com registros contínuos nos períodos de 1969 a 2017 e 1974 a 2017, respectivamente. A série de precipitações pluviométricas foi representada pelos dados da estação Leverger (coordenadas $50^{\circ} 96 \mathrm{~W}$ e $\left.12^{\circ} 99 \mathrm{~S}\right)$, no Mato Grosso (MT), e a série de vazões pelos dados da estação Travessão (coordenadas $50^{\circ} 70 \mathrm{~W}$ e $15^{\circ} 535$ ), em Goiás (GO) (Figura 1).

(comparação) das previsões obtidas nos dois métodos (Figuras 2 e 3). Foram utilizados dois conjuntos de teste, um com 12 observações (ano de 2017) e outro com 24 observações (anos de 2016 e 2017). Foi utilizado o software $R$ (R Project for Statistical Computing) nas análises.

ções de autocorrelação (FAC) e autocorrelação parcial (FACP). A FAC representa a correlação simples entre $Y_{t}$ e $Y_{t-k}$ em função da defasagem $k$. A FAC de uma ST $\left\{Y_{t}\right\}$ pode ser definida por meio da Equação 1: 


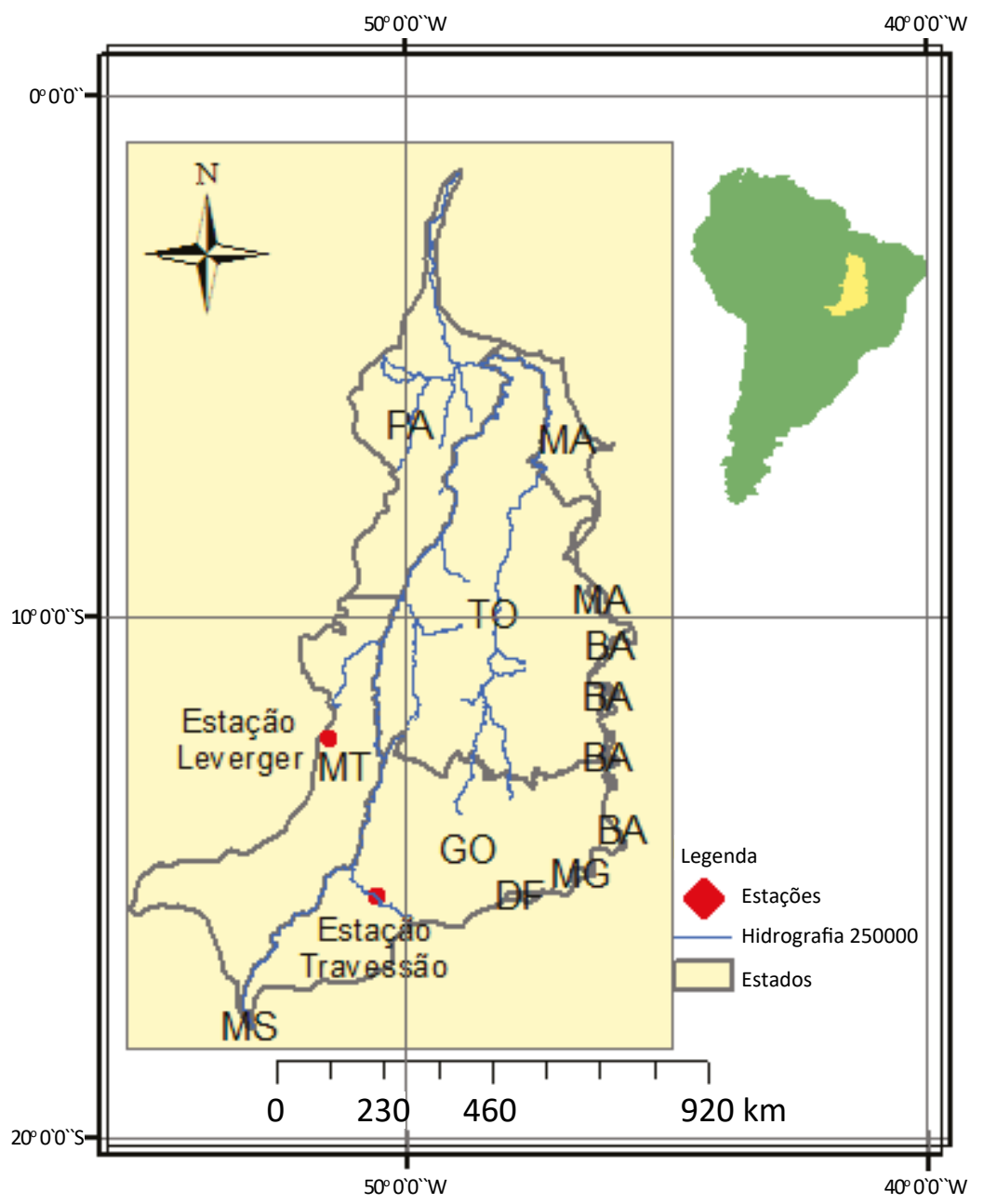

Figura 1 - Bacia Hidrográfica do Araguaia-Tocantins.

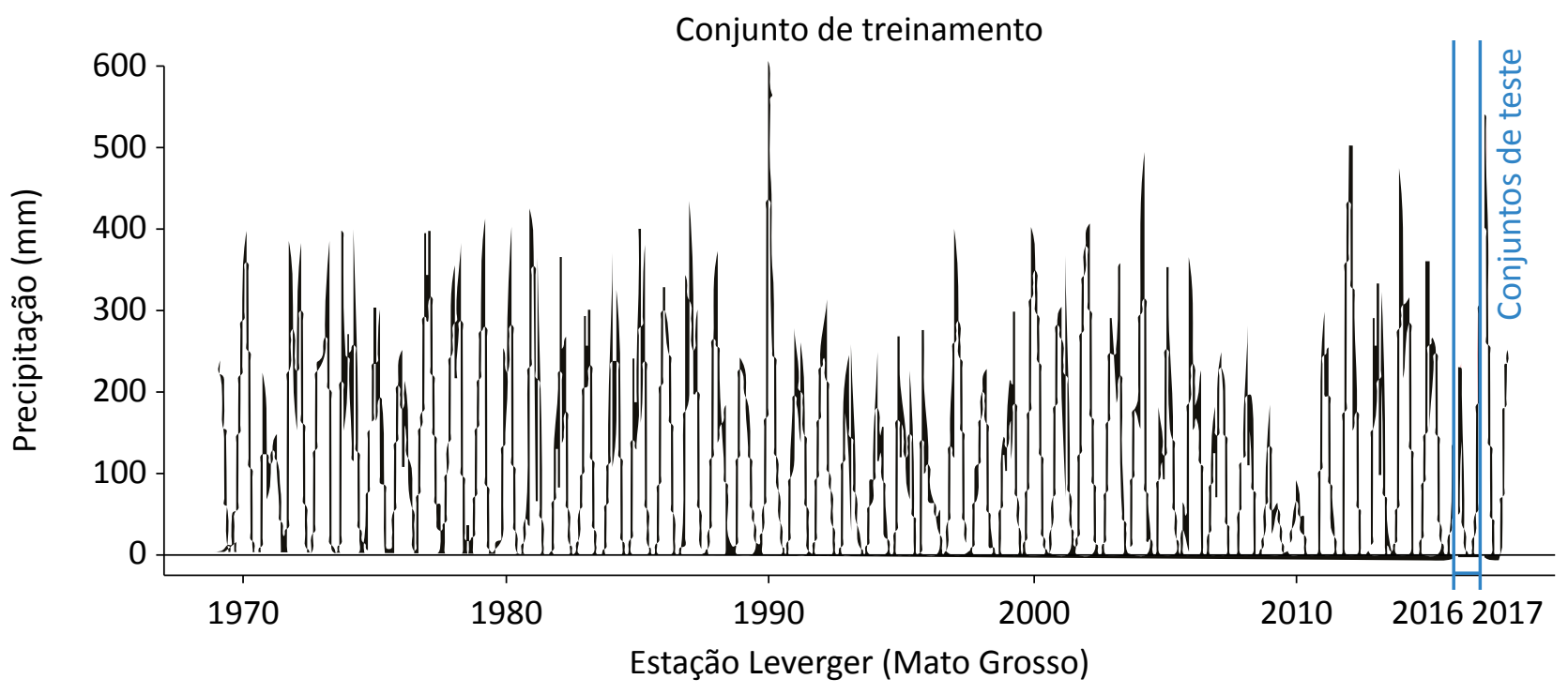

Figura 2 - Série de precipitações mensais na estação Leverger (Mato Grosso) de 1969 a 2017. 


$$
\rho=\frac{\sum_{t=0}^{N-k-1}\left(Y_{t}-\bar{Y}\right)\left(Y_{t+k}-\bar{Y}\right)}{\sum_{t=0}^{N-1}\left(Y_{t}-\bar{Y}\right)^{2}}
$$

Em que:

$N=$ o comprimento da ST;

$\bar{Y}=$ o valor esperado das observações, calculado para a variação temporal (atraso) $k$.

O coeficiente de autocorrelação $(\rho)$ de uma ST varia entre -1 e 1 . Se $\rho$ assume o valor 1 , diz-se que as duas variáveis medidas possuem uma autocorrelação positiva absoluta, caso contrário, se $\rho=-1$, diz-se que a autocorrelação negativa é absoluta. Quando $\rho$ assume valor 0 , não existe autocorrelação entre as variáveis, ou seja, considera-se que as observações são independentes.

A FACP representa a correlação entre $Y_{t}$ e $Y_{t-k}$ como uma função da defasagem $k$, filtrado o efeito de todas as outras defasagens sobre $Y_{\mathrm{t}}$ e $Y_{\mathrm{t}-\mathrm{k}}$. A FACP é definida como a sequência de correlações entre $\left(Y_{t}\right.$ e $\left.Y_{t-1}\right),\left(Y_{t}\right.$ e $\left.Y_{t-2}\right),\left(Y_{t}\right.$ e $\left.Y_{\mathrm{t}-3}\right)$ e assim por diante, desde que os efeitos de defasagens anteriores sobre $t$ permaneçam constantes. A FACP é calculada como o valor do coeficiente $\varphi_{\mathrm{kk}}$ na Equação 2:

$$
Y=\phi_{k 1} Y_{t-1}+\phi_{k 2} Y_{t-2}+\phi_{k 3} Y_{t-3}+\ldots+\phi_{k k} Y_{t-k}+u_{t}
$$

O modelo desenvolvido pela metodologia de BJ, conhecido como ARIMA, consiste basicamente de uma função de regressão populacional para $Y_{\mathrm{t}}$ em que há apenas dois tipos de "variáveis explicativas": a parte "autorregressiva", que representa os valores passados de $Y_{t}$; e a parte "médias móveis", que representa valores presente e passado do distúrbio normal $u_{t}$ (ou "inovação"). A forma geral do modelo (notação Box \& Jenkins, 1976) é dado pela Equação 3:

$Y=\phi_{k 1} Y_{t-1}+\ldots \phi_{p} Y_{t-p}+u_{t}-\theta_{1} u_{t-1}-\ldots-\theta_{q} u_{t-q}$

Em que:

$p=$ a defasagem máxima de $Y_{\mathrm{t}}$ presente na equação;

$q=$ a defasagem máxima de $u_{t}$ (médias móveis) presente na equação;

$\phi_{p}$ e $\theta_{q}=$ os parâmetros (autorregressivos e médias móveis, respectivamente) do modelo a determinar.

O tipo (autorregressivo ou médias móveis) e a quantidade de parâmetros a serem usados nos modelos são determinados pela análise das FAC e FACP. Livros texto, tais como o de Morettin e Toloi (2006), mostram como é feita a escolha dos parâmetros por meio da análise das FAC e FACP. A classe de modelos ARIMA é extremamente flexível. Ela é capaz de produzir, com pouquíssimos parâmetros, ST com os comportamentos mais variados. Em geral, os modelos são apresentados na forma de equações que incluem os operadores $B$, que são operadores diferença, $B^{k} Y_{\mathrm{t}}=Y_{\mathrm{t}-\mathrm{k}^{\prime}}$ de acordo com a Equação 4:

$\phi(B) \Delta^{d} Z_{t}=\theta(B) a_{t}$

Em que:

Conjunto de treinamento

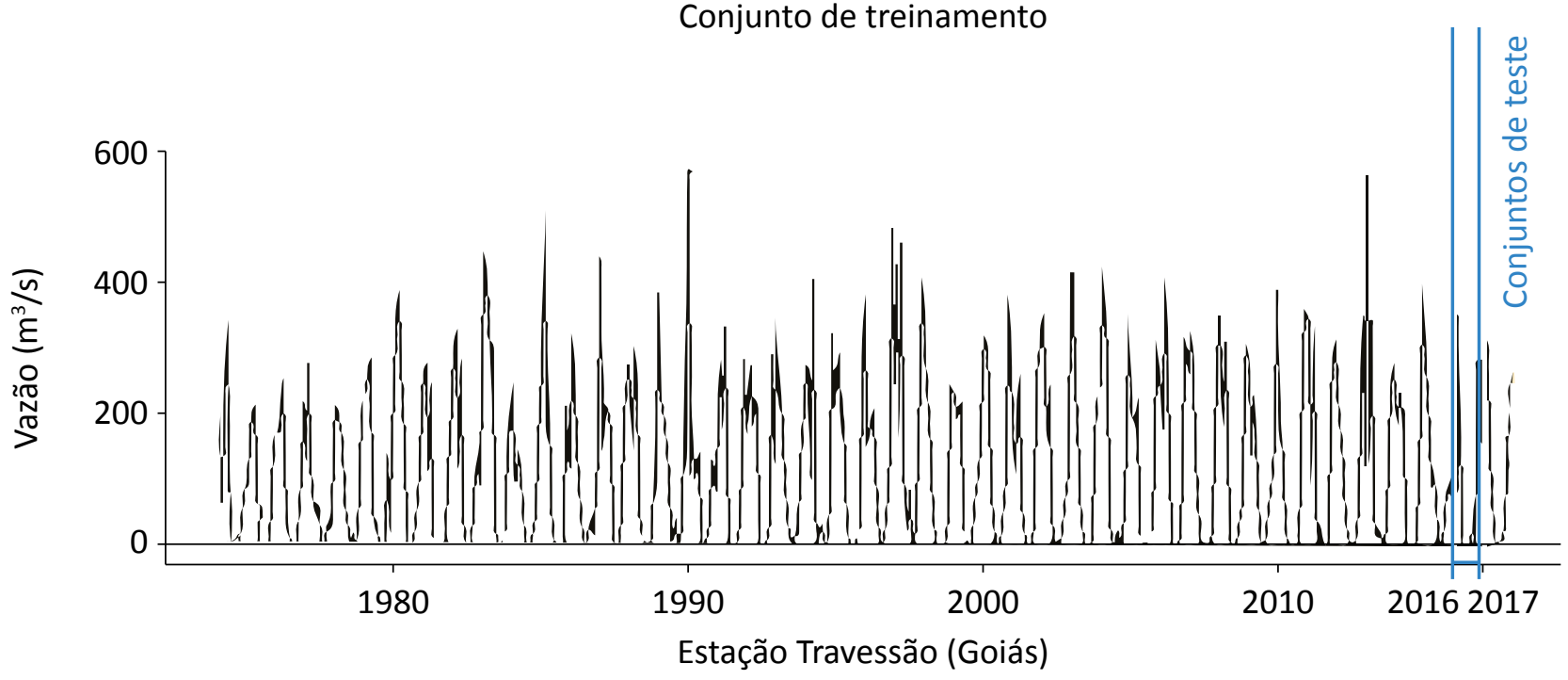

Figura 3 - Série de vazões mensais na estação Travessão (Goiás) de 1974 a 2017. 
$\phi$ e $\theta=$ os parâmetros autorregressivos e médias móveis a serem estimados;

\section{Redes neurais artificiais}

As RNA são técnicas computacionais cujo funcionamento baseia-se na estrutura neural de seres vivos e que realizam tarefas de computação adquirindo conhecimento por meio de experiência, construída por um processo de aprendizagem, tendo como principais vantagens as características de adaptabilidade, generalização e tolerância a falhas (HAYKIN, 2001 apud BONFANTE et al., 2013).

Considerado um método alternativo ao modelo ARIMA na previsão de ST, as RNA possuem variada característica destacável (HAYKIN, 2001; SMITH, 1996). Uma das principais é como um aproximador universal, ou seja, uma RNA pode estimar qualquer função contínua não linear com um bom grau de precisão (DU; HOU; LI, LAGARIS; LIKAS; FOTIADIS, 1998; ZHANG, 2003). Neste trabalho foi utilizada a rede tipo perceptron de múltiplas camadas (multilayer perceptron - MLP). Nesse tipo de rede, o sinal de entrada propaga-se para frente (feedforward), camada por camada, sendo em seguida retropropagado para a correção do erro (ajuste dos pesos sinápticos). Esse procedimento é repetido durante várias iterações até a finalização do treinamen-
$\Delta^{\mathrm{d}}=(1-B)^{\mathrm{d}}=\mathrm{o}$ operador diferença, utilizado para tornar a série estacionária, se necessário.

to (ZANETTI, 2008 apud BONFANTE et al., 2013). A Figura 4 mostra um MLP feedforward com $n$ entradas, uma camada oculta com m neurônios e um neurônio na camada de saída. Tal topologia de RNA é a mais comum na previsão de ST (KHANDELWAL \& VERMA, 2015; ZHANG, 2003; ABHISHEK et al., 2012). Para essa situação temos o seguinte modelo matemático (Equação 5):

$\left\{\begin{array}{l}z=b_{0 j}+W X j=1,2, \ldots, n \\ y_{t}=b_{0}+V \sigma(Z)+\varepsilon_{t}\end{array}\right.$

Em que:

$W=\left[w_{i j}\right]$ e $V=\left[v_{j 1}\right](i=1,2, \ldots, m ; j=1,2, \ldots, n)=$ matrizes contendo os pesos sinápticos;

$X=\left(x_{1}, x_{2}, \ldots, x_{n}\right)^{\top}=0$ vetor contendo os dados de entrada (nesse caso, são os elementos da série temporal);

$b_{o}$ e $b_{o j}$ são os bias;

$\varepsilon_{t}=$ o ruído branco em cada amostra;

$\sigma()=$. a função de ativação, que para problemas envolvendo ST é adotada a função logística (KHANDELWAL \& VERMA, 2015; ZHANG, 2003).

\section{Procedimentos utilizados na comparação entre}

\section{redes neurais artificiais e modelos de séries temporais}

Com base nas análises das FAC e FACP foram construídos dois modelos de ST para cada série, baseados em períodos diferentes. Com o modelo da série de precipitações pluviométricas da estação Leverger (MT) de

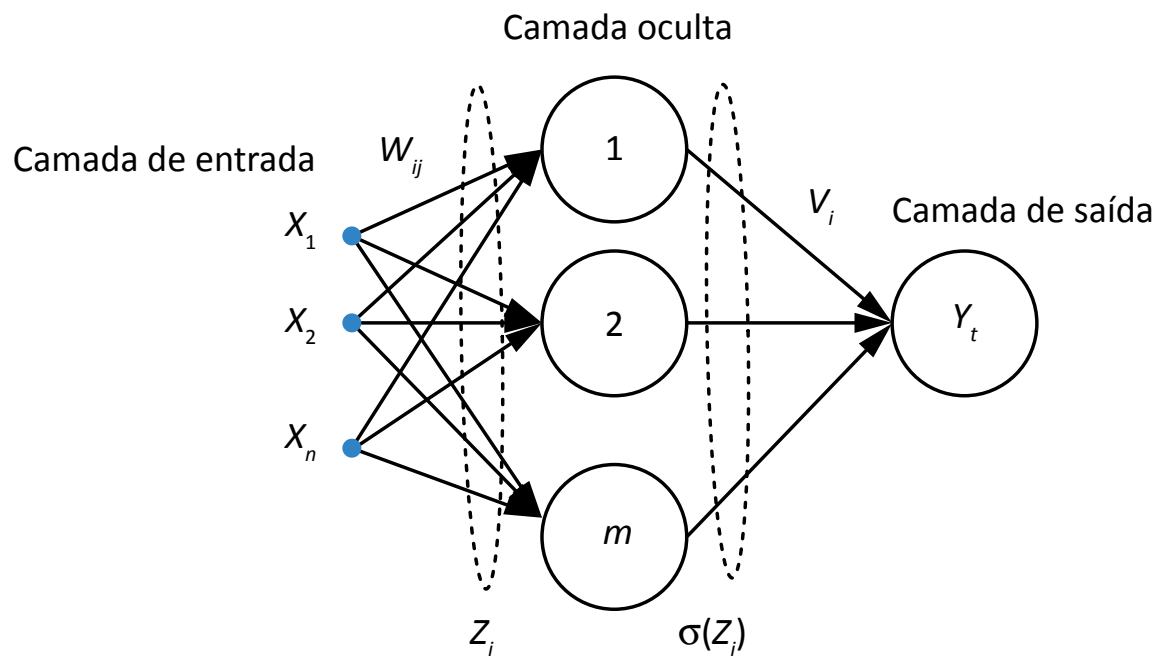

Figura 4 - Perceptron multicamada com uma camada oculta. 
1969 a 2016 foram estimados 12 valores mensais para o ano de 2017. Para outro modelo ajustado na mesma série de 1969 a 2015 foram estimados 24 valores mensais para os anos de 2016 e 2017. Esses valores estimados foram comparados com os valores reais observados, de modo que se pôde avaliar a qualidade das previsões de cada modelo. Nesse caso, na avaliação de cada valor estimado (comparação com o valor observado) foram utilizados testes de hipóteses com base em intervalos de confiança de $95 \%$ (IC95\%). O mesmo procedimento foi utilizado na série de vazões da estação Travessão (GO). Utilizando-se as mesmas séries utilizadas nas construções dos modelos de séries temporais para as estações Leverger e Travessão como conjuntos de treinamento para RNA, foram realizadas 20 repetições ou simulações (previsões) de 12 e 24 meses para cada série: série de precipitações pluviométricas da estação Leverger, para o ano de 2017 (12 meses) e anos de 2016-2017 (24 meses); o mesmo procedimento foi repetido para a série de vazões da estação Travessão. Para representar as 12 e 24 previsões foram considerados os valores médios das 20 simulações realizadas para cada mês. Em seguida, esses valores foram comparados com as previsões feitas pelo método de BJ e calculada a raiz quadrada do erro quadrado médio (root mean square error-RMSE) para cada série.

\section{RESULTADOS E DISCUSSÃO}

De acordo com o exposto na metodologia, inicialmente foram consideradas as séries de precipitações pluviométricas e vazões até dezembro de 2016. Nesse caso, oano de 2017 foi utilizado como conjunto de teste para validação dos modelos, ou seja, utilizado nas comparações dos valores observados com as previsões geradas pelos métodos de BJ e RNA. Em seguida, foram utilizadas as séries até dezembro de 2015 ficando os anos de 2016 e 2017 como conjuntos de teste (Figuras 2 e 3).

Nas Figuras 5 e 6 são apresentadas as FAC e FACP utilizadas na identificação dos modelos de séries temporais na metodologia de BJ. Pode-se observar, principal- mente nas FAC das duas séries (Leverger e Travessão), a presença de uma componente sazonal provavelmente no lag 12.

As Equações 6 a 9 são os modelos de BJ ajustados para as precipitações pluviométricas da série Leverger e de vazões para a série Travessão. As Equações 7 e 9 são para as séries até dezembro de 2016; e as Equações 8 e 10 são para as séries até dezembro de 2015. Com os modelos das Equações 7 e 9 foram calculadas 12 previsões mensais para o ano de 2017; e com os modelos das Equações 8 e 10 foram calculadas 24 previsões mensais para os anos de 2016 e 2017 . Nesses modelos,
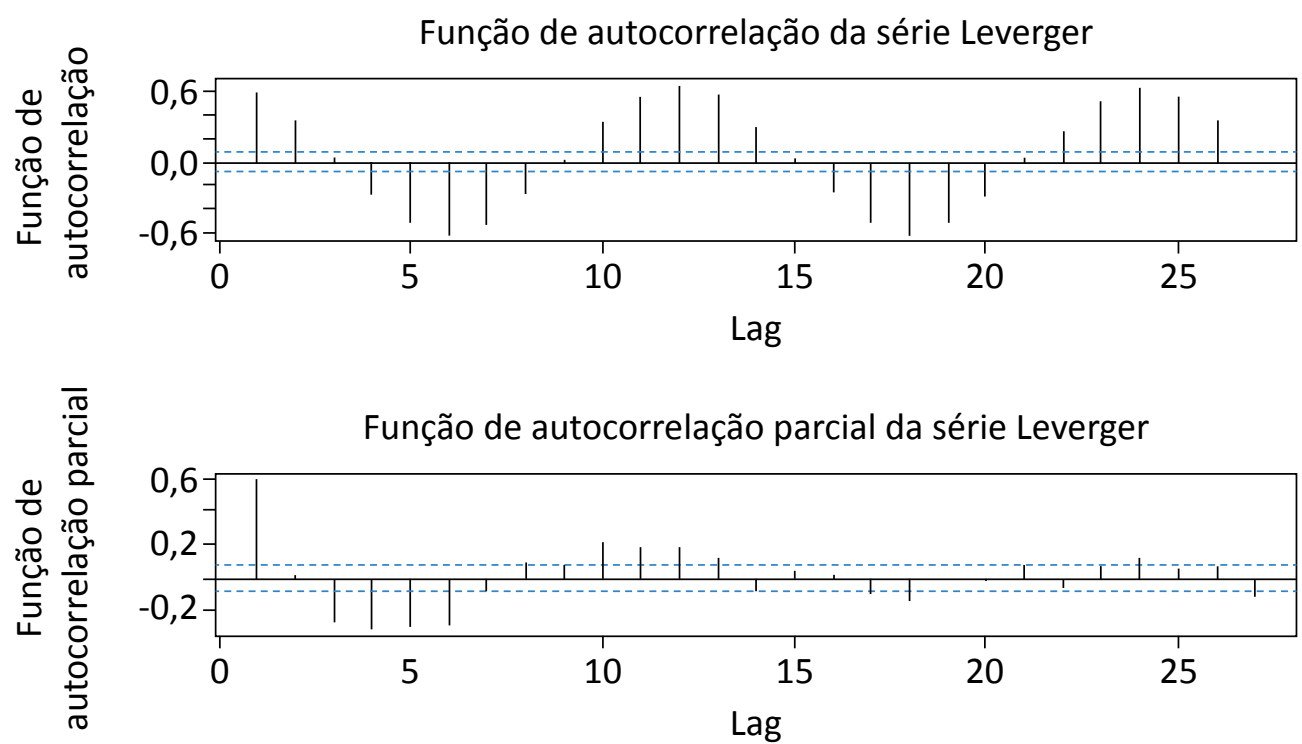

Figura 5 - Função de autocorrelação e função de autocorrelação parcial para as precipitações mensais. Série Leverger. 
$Y_{t}$ indica a série (precipitação pluviométrica ou vazão), $a_{t^{\prime}}$ o ruído, $B$ é o operador diferença, $B^{k} Y_{t}=Y_{t-k^{\prime}}$ é o nível descritivo e $p$ é fornecido abaixo de cada estimativa dos parâmetros do modelo. Praticamente todos os parâmetros estimados foram significativos, com probabilidades de erro abaixo de $5 \%$.

$$
\begin{aligned}
& \underset{p<0,002}{(1-0,128 B}-\underset{p<0,022}{0,096 B^{2}}-\underset{p<0,031}{0,0907 B^{10}-} \\
& \left.\left.\underset{p<0,067}{0,1005 B^{13}}\right) Y_{t}=\underset{p<0,0001}{0,0,982 B^{12}}\right) a_{t} \\
& \underset{p<0,0001}{(1-0,141 B}-\underset{p<0,0205}{0,099} B^{2}-0,0931 B^{10}- \\
& \left.\left.\underset{p<0,0304}{0,0921 B^{13}}\right) Y_{t}=\underset{p<0,0001}{\left(1-0,999^{12}\right.}\right) a_{t} \\
& \left.\underset{p<0,0001}{\left(1-0,9982 B^{12}\right.}\right) Y_{t}=\underset{p<0,0001}{119,35+} \\
& \left.\underset{p<0,0589}{\left(1-0,0815 B^{2}\right.}\right)\left(1+\underset{p<0,0001}{0,9097 B^{12}}\right) a_{t} \\
& \left.\underset{p<0,0001}{\left(1-0,9987 B^{12}\right.}\right) Y_{t}=\underset{p<0,0001}{116,3847+} \\
& \left.\underset{p<0,0135}{\left(1-0,1077 B^{2}\right.}\right)\left(\underset{p<0,0001}{0,92655 B^{12}}\right) a_{t}
\end{aligned}
$$

Depois de identificados os modelos e os parâmetros estimados, a verificação diagnóstica deve ser feita para garantir que os modelos são adequados. Isso pode ser feito usando o teste Box-Pierce ou Ljung-Box. Para verificação de diagnóstico, a hipótese nula é que os resíduos são independentes, com média igual a zero e variância constante. O teste de Box-Pierce para todos os modelos apresentou valores de $\mathrm{p}$ (nível descritivo) maiores do que 0,05 . Portanto, aceitamos a hipótese nula de que o os resíduos são independentes e os modelos podem ser considerados adequados. Isso pode ser confirmado nos gráficos dos resíduos apresentados nas Figuras 7 e 8.

Nas Figuras 9 e 10 são apresentadas as previsões (em linha contínua azul) de 12 meses (2017) e 24 meses (2016 e 2017) estimadas a partir dos modelos de BJ paras as séries de precipitação pluviométrica (Leverger) e vazões (Travessão). Foram utilizados IC95\% (área cinza das Figuras 9 e 10) para cada estimativa. Para a realização dos testes de hipóteses com base nesses intervalos, foram plotados os valores observados (em linha tracejada azul) de precipitações pluviométricas e vazões. As conclusões apontam para a aceitação da hipótese - H0: não há diferença estatística entre $\mu$ (estimativa) e $\mu_{0}$ (valor observado) - , pois todos os valores (estimados e observados) se encontram dentro do IC95\%, exceto para fevereiro de 2016 e 2017 na estação Leverger e janeiro e novembro de 2016 para a estação Travessão.

As mesmas séries foram utilizadas na aplicação de RNA. Os resultados obtidos para os mesmos conjuntos de treinamento e conjunto de testes são apresentados a seguir. A Figura 11 mostra o desenho do modelo MLP da rede neural utilizada, com 12 entradas,
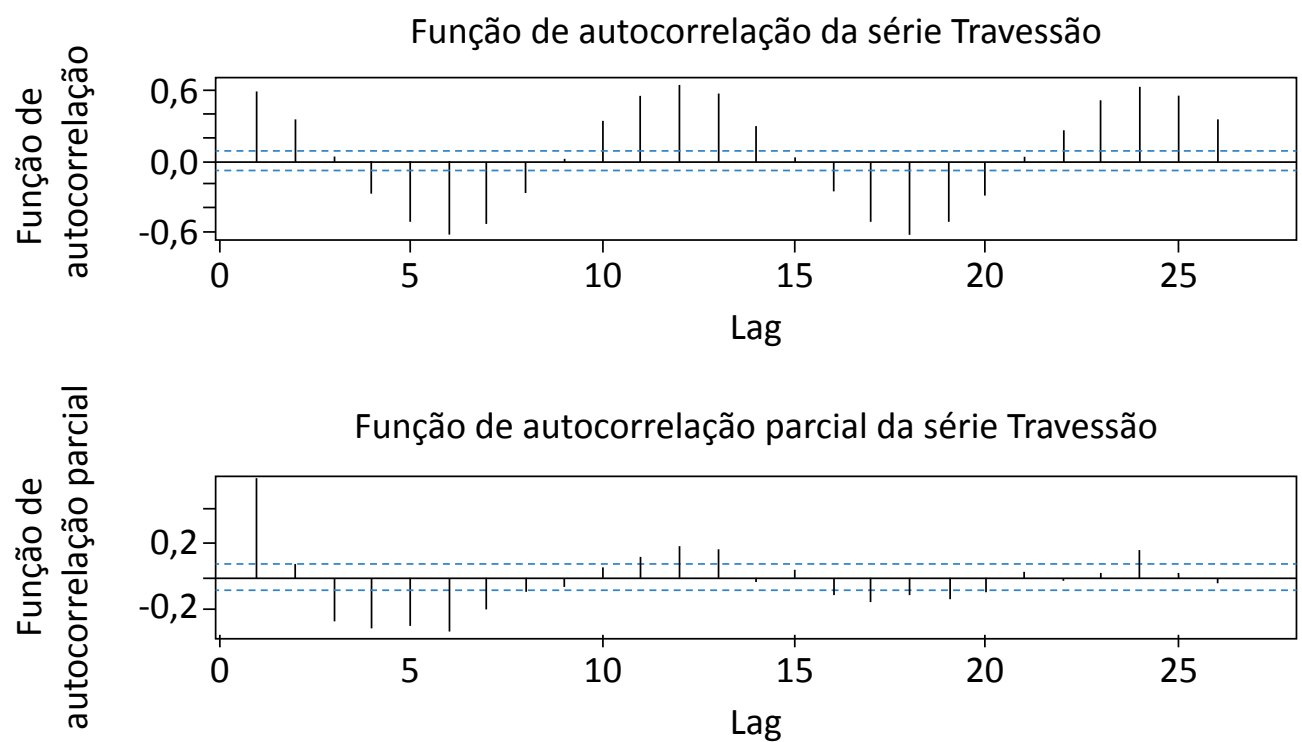

Figura 6 - Função de autocorrelação e função de autocorrelação parcial para as vazões mensais. Série Travessão. 
referentes aos meses de cada ano e 5 camadas ocultas. Foram feitas 20 repetições ou simulações (previsões) para cada série, para os anos de 2017 e 20162017. Os resultados são mostrados na Figura 12 para a série Leverger e na Figura 13 para a série Travessão. As linhas pretas representam as simulações e a linha azul mais grossa mostra as médias das 20 simulações feitas para cada mês. Essas médias foram consideradas as previsões de redes neurais, utilizadas nas comparações entre os métodos.
Nas Figuras 14 e 15 são mostrados os resultados das previsões obtidas pelos métodos de BJ e redes neurais, além dos IC95\% das estimativas dos modelos de BJ e os valores observados de precipitações pluviométricas e vazões. Com base nos IC95\%, os testes de hipóteses para comparação dos valores individuais das previsões pelos modelos de BJ e pelo método RNA mostram não haver diferenças estatisticamente significativas entre eles, uma vez que todos os valores previstos estão inseridos dentro do IC95\%. Ou seja, pode-se considerar,
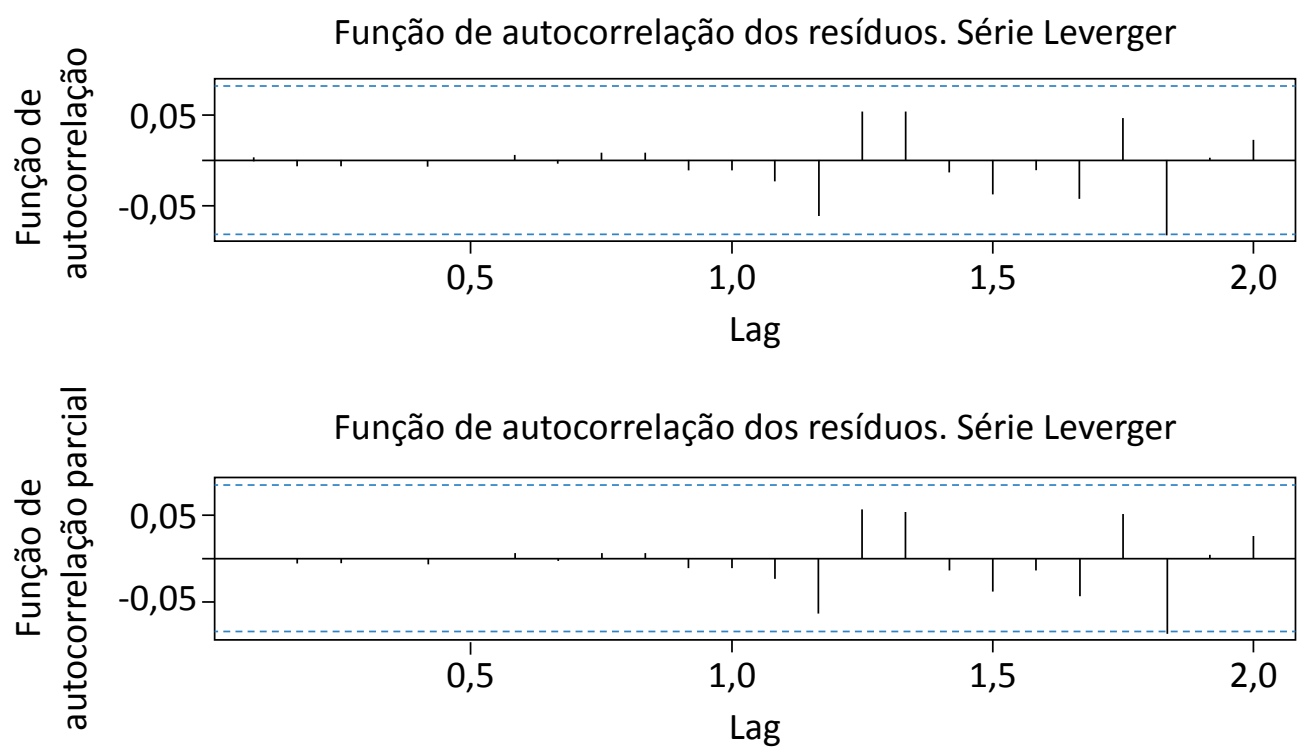

Figura 7 - Função de autocorrelação e função de autocorrelação parcial dos resíduos para as precipitações mensais. Série Leverger.
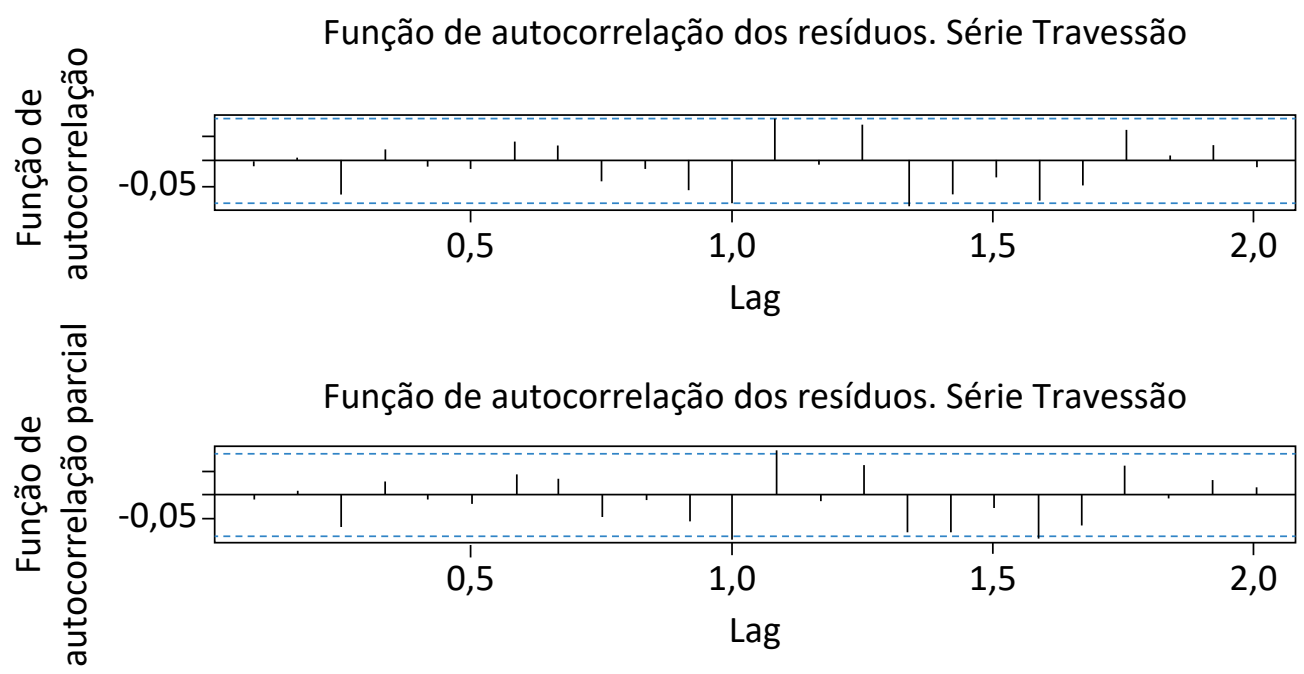

Figura 8 - Função de autocorrelação e função de autocorrelação parcial dos resíduos para as vazões mensais. Série Travessão. 
com risco de erro de menos de $5 \%$, que as previsões obtidas por redes neurais e modelos de BJ não apresentam diferenças estatisticamente significativas. Quando as previsões obtidas por RNA e BJ são comparadas com os valores observados, com exceção do mês de janeiro de 2017 para precipitações pluviométricas e dos meses de janeiro e novembro de 2017 para vazões, as diferenças são estatisticamente não significativas, ou seja, os dois modelos conseguem realizar boas previsões, mesmo para séries com grande variabilidade, como as que foram analisadas.

Muitos trabalhos que se propuseram a comparar a metodologia de BJ com o método RNA utilizaram o RMSE como medida de comparação da performance das previsões obtidas por cada método. Por exemplo, Khandelwal e Verma (2015) compararam previsões de BJ e RN em quatro ST (Lynx, Exchange rate,
Indian mining e US temperature). Em duas dessas séries (Indian mining e US temperature, com 30 e 60 previsões, respectivamente) o modelo BJ apresentou RMSE menor do que o método de redes neurais. Nas séries Lynx e Exchange rate, com 14 e 52 previsões, respectivamente, o método RMSE da RNA foi menor. Shuhaili Safee e Sabri Ahmad (2014) utilizaram série de índices climáticos em Sitiawan, Perak, Malásia, na comparação de previsões obtidas com vários métodos estatísticos, incluindo modelos de BJ e redes neurais. Os modelos $B J$ apresentaram menores RMSE e erro percentual médio absoluto (MAPE) tanto na parte de treinamento da série quanto no conjunto de teste ou avaliação. Neste trabalho, a Tabela 1 mostra que em todos os casos os modelos baseados na metodologia de BJ apresentaram RMSE de previsões menores do que a RNA. Pode-se observar que, em geral, nos gráficos das Figuras 14 e 15,
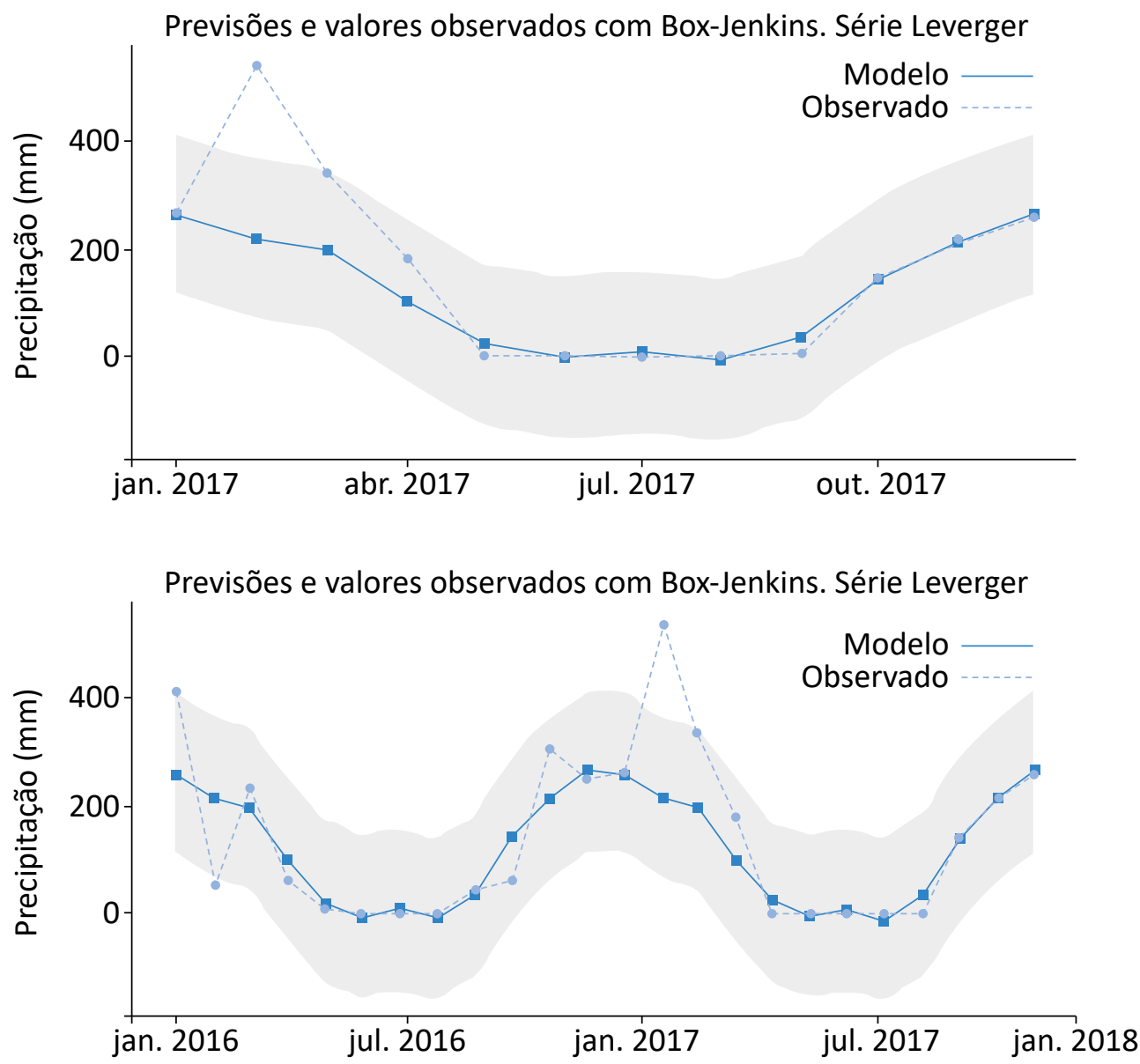

Figura 9 - Previsões com modelo Box-Jenkins e valores observados para precipitação pluviométricas na estação Leverger para 2017 (acima) e 2016-2017 (abaixo) com intervalo de confiança de 95\% (área cinza). 


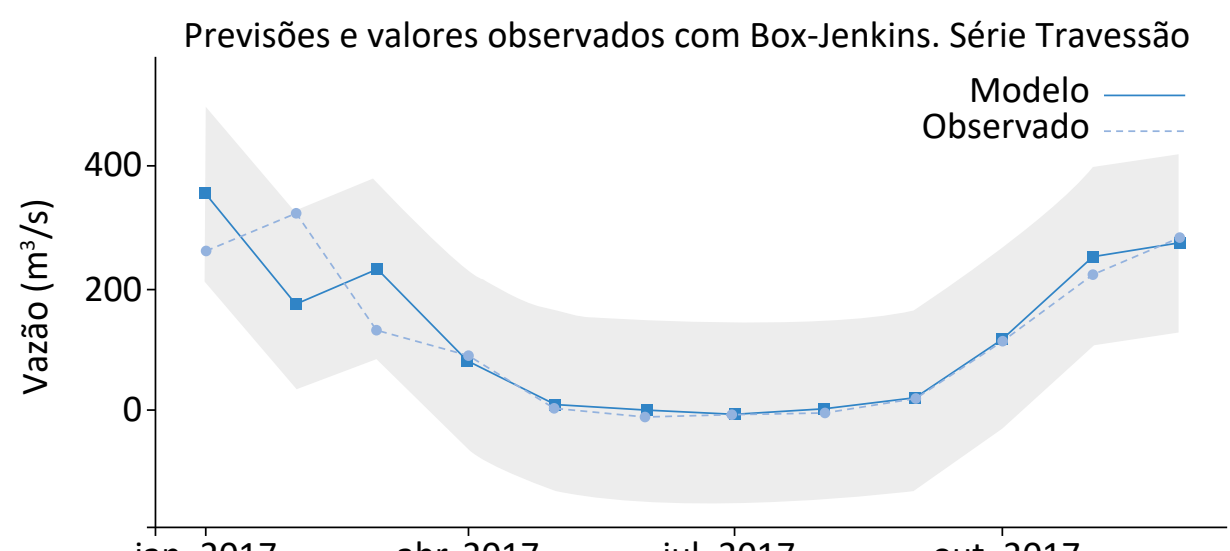

jan. $2017 \quad$ abr. $2017 \quad$ jul. $2017 \quad$ out. 2017

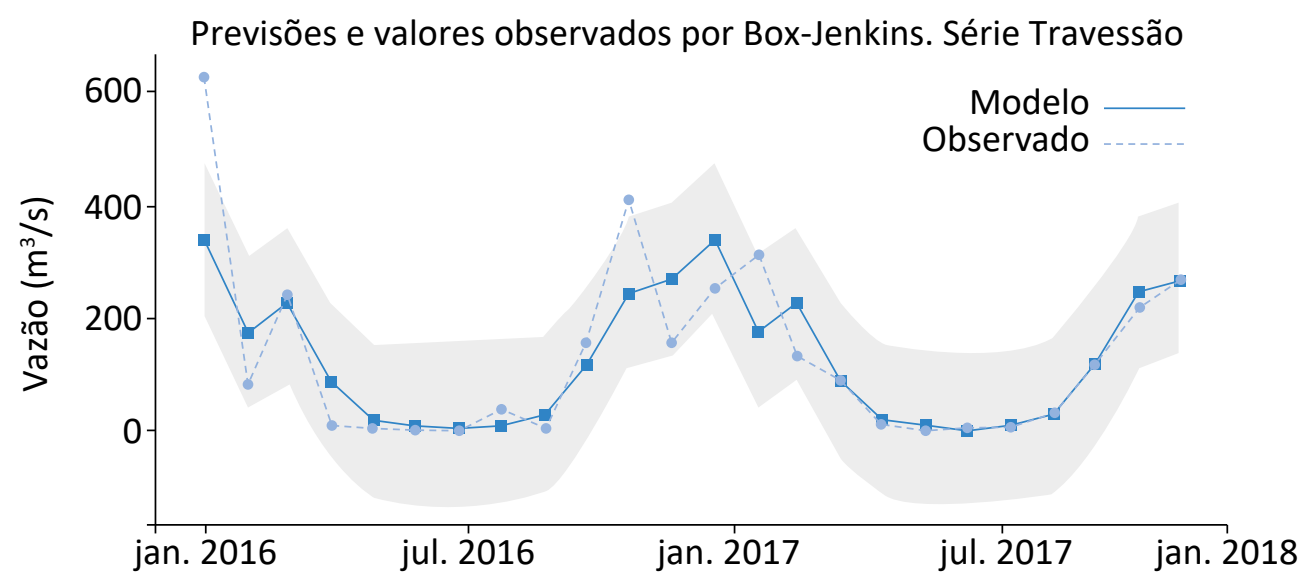

Figura 10 - Previsões com modelo Box-Jenkins e valores observados para vazões na estação Travessão para 2017 (acima) e 2016-2017 (abaixo) com intervalo de confiança de 95\% (área cinza).

Perceptron de múltiplas camadas

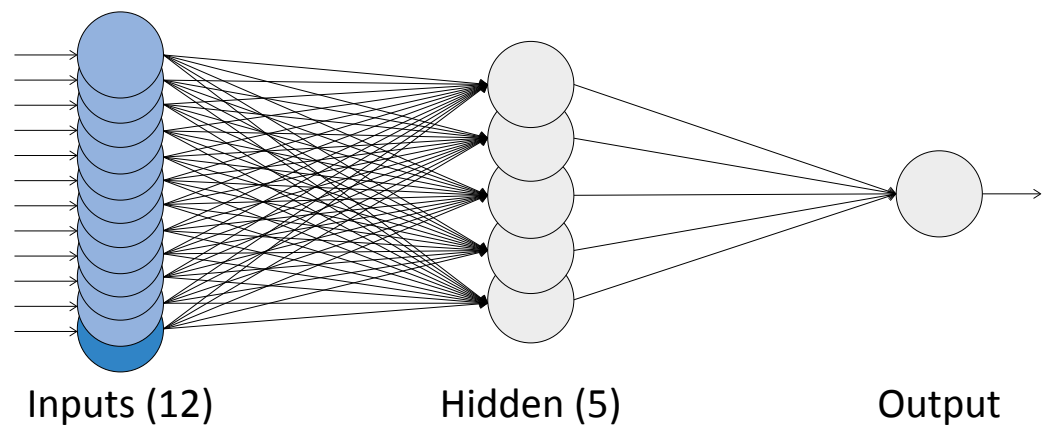

Figura 11 - Diagrama do modelo perceptron de múltiplas camadas (MLP) da rede neural utilizada, com 12 entradas e 5 camadas ocultas. 
Previsões com redes neurais. Série Leverger

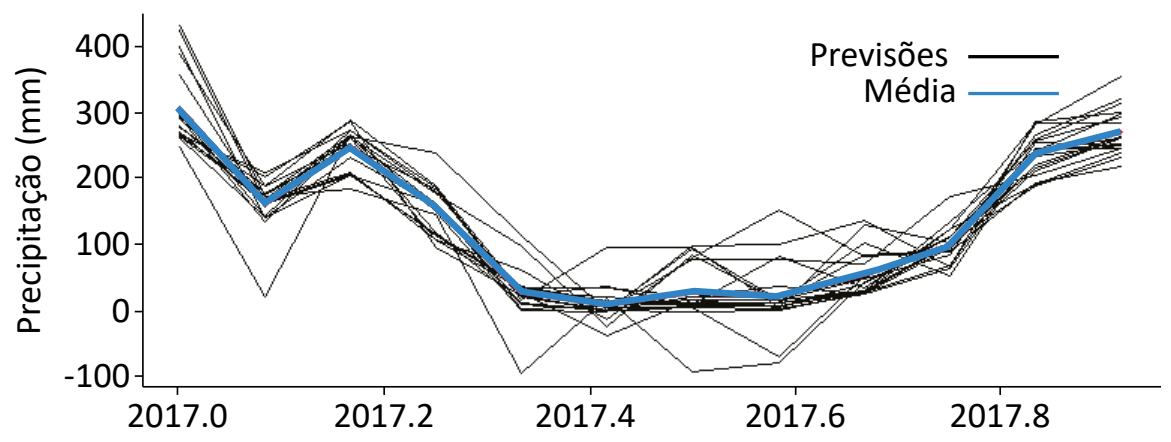

Previsões com redes neurais (24 meses). Série Leverger

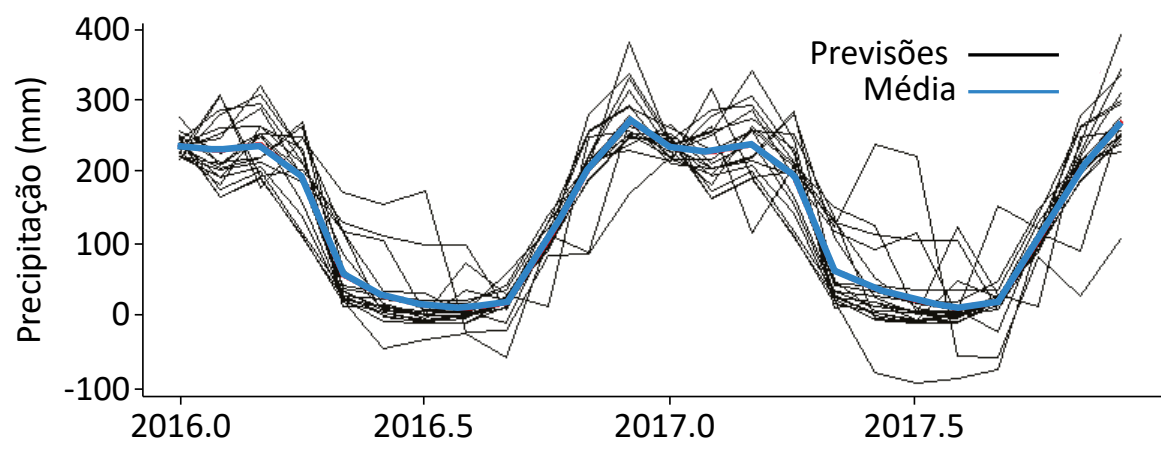

Figura 12 - Previsões com redes neurais artificiais para precipitações na estação Leverger para 2017 (acima) e $2016-2017$ (abaixo).

Previsões com redes neurais. Série Travessão

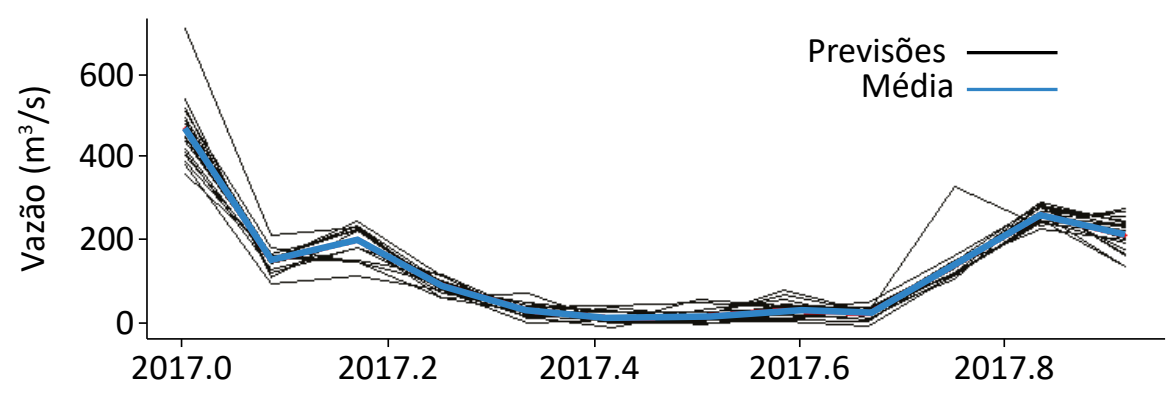

Previsões com redes neurais (24 meses). Série Travessão

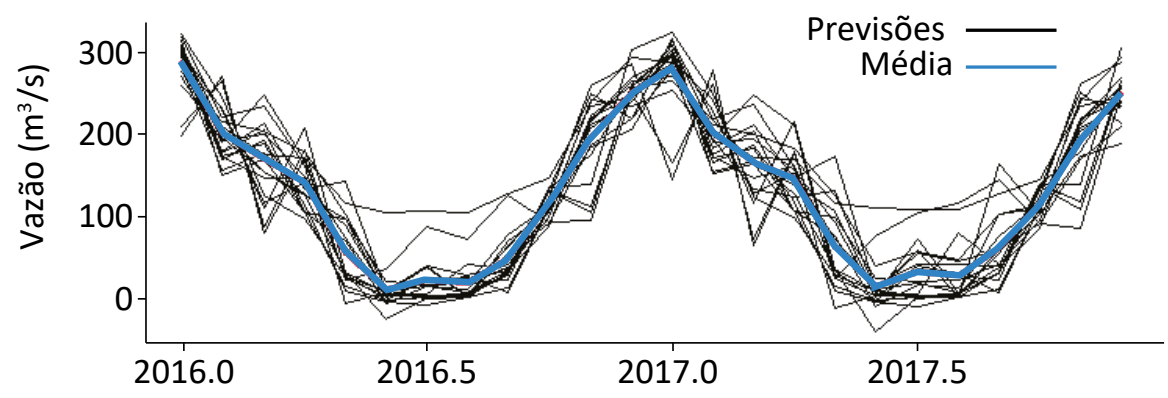

Figura 13 - Previsões com redes neurais artificiais para vazões na estação Travessão para 2017 (acima) e $2016-2017$ (abaixo). 
as estimativas obtidas por BJ estão mais próximas dos valores observados em relação às de RNA. Na estação Travessão as vazões apresentaram menores RMSE de previsões nos dois métodos.

\section{CONCLUSÕES}

Os resultados deste trabalho mostram que previsões obtidas por redes neurais com o método MLP e modelos de BJ não apresentam diferenças estatisticamente significativas, além de se obter boas previsões na utilização desses métodos. As comparações baseadas em valores médios como RMSE ou MAPE podem não retratar com precisão a comparação entre os métodos, uma vez que médias podem ser influenciadas por valores extremos. Nesse sentido, a média só representa adequadamente conjuntos com distribuições simétricas, ou seja, sem a presença de valores extremos. A RMSE, por exemplo, apresenta a tendência de penalizar grandes erros de previsão mais do que outras me- didas. Por isso se considera a medida mais apropriada para determinar os métodos que apresentam grandes erros.

Entretanto, a escolha da metodologia a ser utilizada deve considerar alguns aspectos relevantes de cada método. Se a preferência for pela metodologia de BJ, é importante que se tenha capacitação em métodos estatísticos. Os métodos estatísticos de ST são limitados pelos pressupostos subjacentes do modelo, como estacionariedade, sazonalidade ou duração da série temporal. O uso de modelos probabilísticos em ST permite que se tenha, em qualquer caso, uma medida da

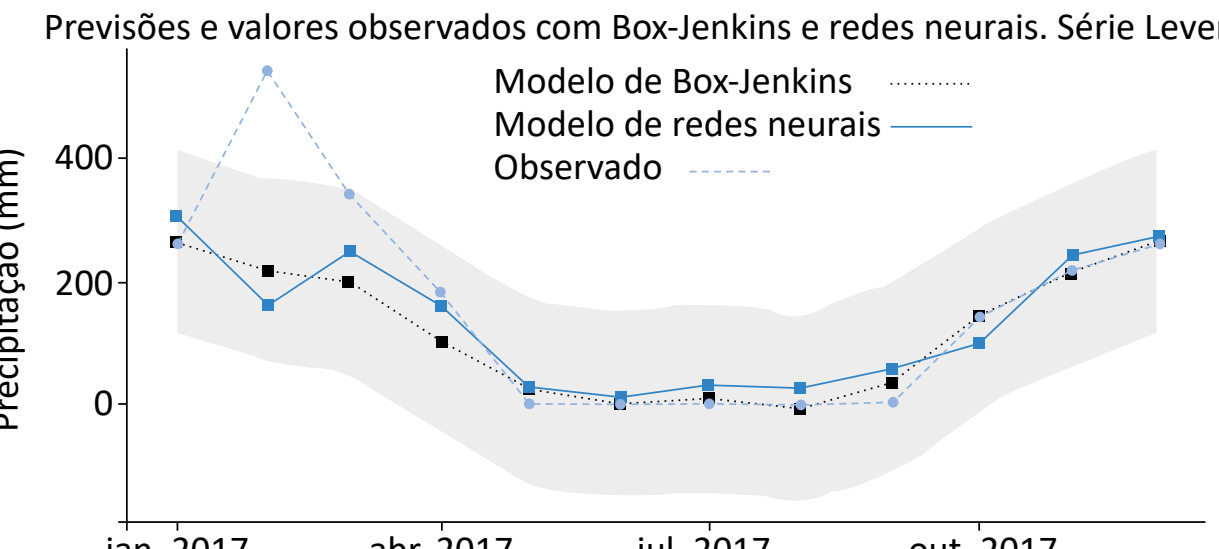

jan. $2017 \quad$ abr. $2017 \quad$ jul. $2017 \quad$ out. 2017

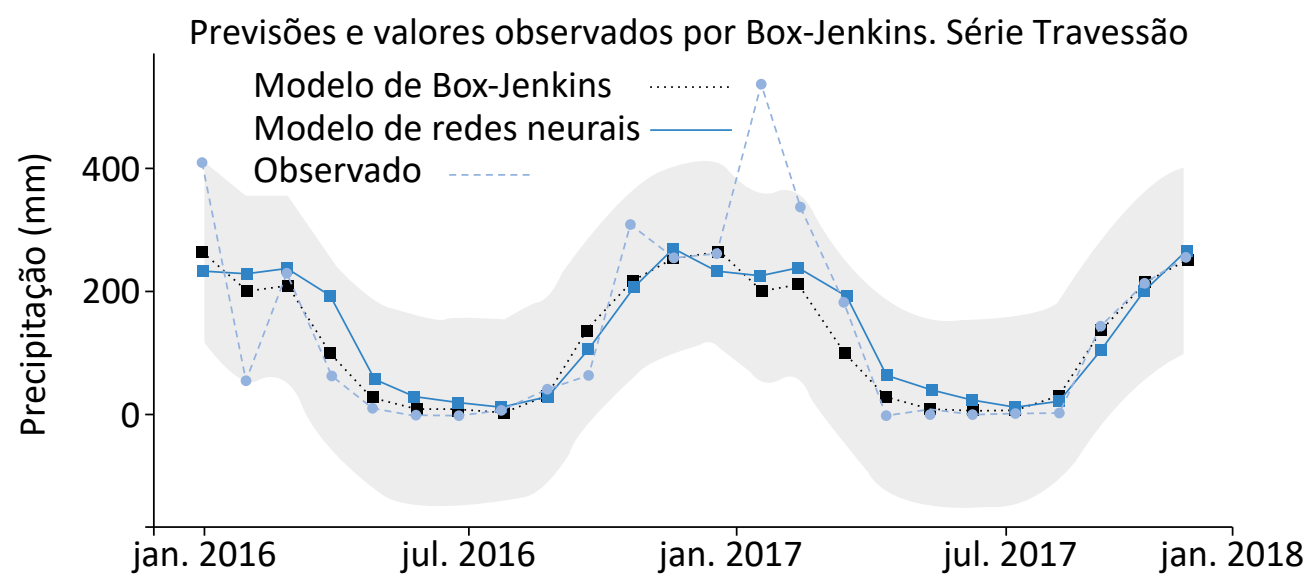

Figura 14 - Previsões com Box-Jenkins e redes neurais artificiais para precipitações na estação Leverger para 2017 (acima) e 2016-2017 (abaixo). Em cinza, intervalo de confiança de 95\%. 
Previsões e valores observados com Box-Jenkins e redes neurais. Série Travessão

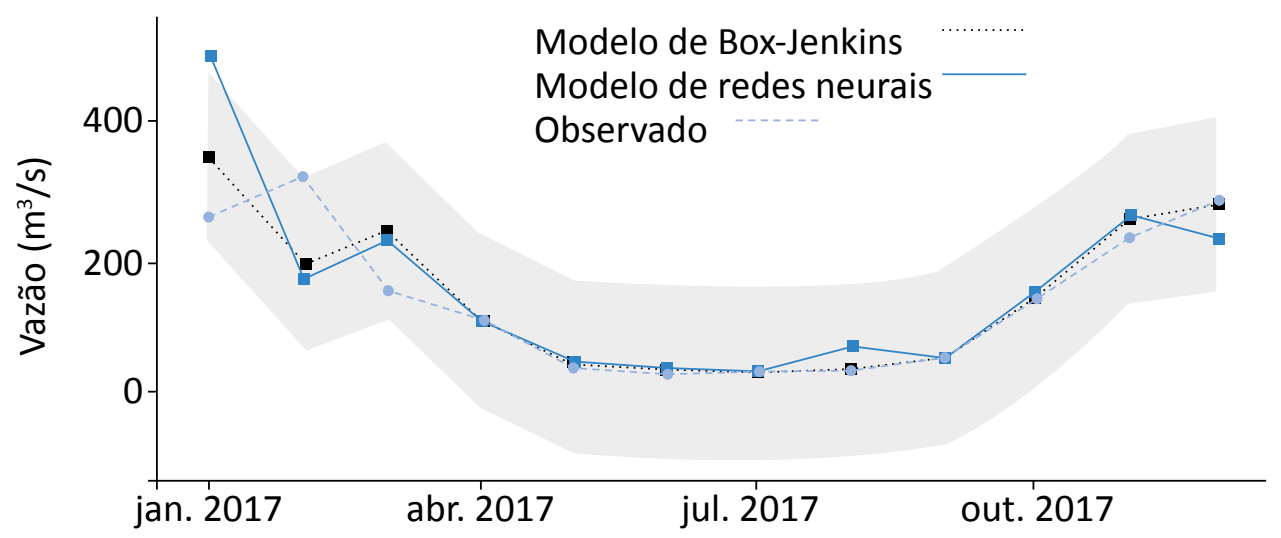

Previsões e valores observados por Box-Jenkins. Série Travessão

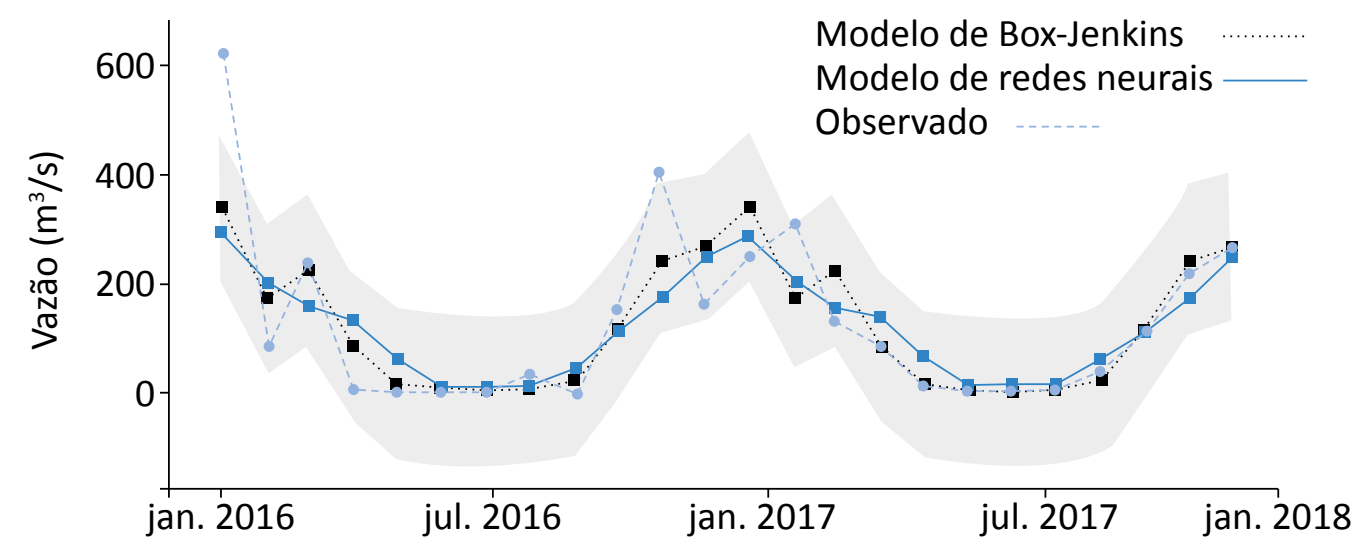

Figura 15 - Previsões com Box-Jenkins e redes neurais artificiais para vazões na estação Travessão para 2017 (acima) e 2016-2017 (abaixo). Em cinza, intervalo de confiança de 95\%.

Tabela 1 - Medidas dos erros (RMSE) nas previsões para cada modelo.

\begin{tabular}{|l|c|c|c|}
\hline Estação & Tipo de modelo & Número de previsões (ano) & Erro (RMSE) \\
\hline & Box-Jenkins (Equação 1) & $12(2017)$ & 105,5486 \\
\hline Leverger & Redes neurais (MLP) & 116,5135 \\
\hline & Box-Jenkins (Equação 2) & $24(2016$ e 1017) & 91,7132 \\
\hline & Redes neurais (MLP) & 94,7158 \\
\hline Travessão & Box-Jenkins (Equação 3) & $12(2017)$ & 55,3284 \\
\hline & Redes neurais (MLP) & & 93.1440 \\
\hline & Box-Jenkins (Equação 4) & $24(2016$ e 1017) & 85,4241 \\
\hline
\end{tabular}

RMSE: root mean square error; MPL: multilayer perceptron. 
incerteza nas previsões obtidas. É preferível, ainda que se tenha experiência nessa área, uma vez que séries com alta variabilidade apresentam maior grau de dificuldade na modelagem. Modelos de redes neurais, ao contrário, não têm as limitações dos modelos estatísticos incluindo ruído, amostragem irregular ou tama- nho da série temporal, mas podem apresentar outras desvantagens, tais como o tempo computacional e dificuldade de fornecer explicações sobre os dados. Sendo um método de inteligência artificial que não usa modelos estatísticos, não se tem uma medida de incerteza das previsões.

\section{REFERÊNCIAS}

ABHISHEK, K.; SINGH, M. P.; GHOSH, S.; ANAND, A. Weather Forecasting Model Using Neural Network. Procedia Technology, v. 4, p. 311-318, 2012. https://doi.org/10.1016/j.protcy.2012.05.047

AGÊNCIA NACIONAL DE ÁGUAS (ANA). Disponibilidade e demandas de recursos hídricos no Brasil. Brasília: Ministério do Meio Ambiente; 2005.

BONFANTE, A.; VENTURA, T.; OLIVEIRA, A.; MARQUES, H.; OLIVEIRA, R.; MARTINS, C.; FIGUEIREDO, J. Uma abordagem computacional para preenchimento de falhas em dados micro meteorológicos. Revista Brasileira de Ciências Ambientais, n. 27, p. 61-70, 2013. Disponível em: <http://rbciamb.com.br/index.php/Publicacoes_RBCIAMB/article/view/299>. Acesso em: 10 jan. 2018.

BOX, G. E. P.; JENKINS, G. Time series analysis, forecasting and control. San Francisco: Holden-Day, 1976.

CAMARGOS, V. P.; CÉSAR, C. C.; CAIAFFA, W. T.; XAVIER, C. C.; PROIETTI, F. A. Multiple imputation and complete case analysis in logistic regression models: a practical assessment of the impact of incomplete covariate data. Cadernos Saúde Pública, Rio de Janeiro, v. 27, n. 12, p. 2299-2313, dez. 2011. https://doi.org/10.1590/s0102-311x2011001200003

CHECHI, L.; SANCHES, F. O. Análise de uma Série Temporal de Precipitação para Erechim (RS) e um Possível Método de Previsão Climática. Ambiência, v. 9, n. 1, p. 43-55, 2013. https://doi.org/10.5777/ambiencia.2013.01.03

CHOON, O. H. \& CHUIN, J. L. T. A comparison of Neural Network Methods and Box-Jenkins Model in Time Series Analysis. In: IASTED INTERNATIONAL CONFERENCE, ADVANCES IN COMPUTER SCIENCE AND TECHNOLOGY, 4., 2008, Langkawi. Anais... 2008.

DU, L. M.; HOU, Z. Q.; LI, Q. H. Optimum blockadaptive learning algorithm for error back-propagation networks, IEEE Transactions on Signal Processing, v. 40, n. 12, p. 3032-3042, 1992. https://doi.org/10.1109/78.175746

HAYKIN, S. Redes Neurais: Princípios e Práticas. 2. ed. Porto Alegre: Bookman, 2001.

HO, S. L.; XIE, M.; GOH, T. N. A Comparative Study of Neural Network and Box-Jenkins ARIMA Modeling in Time Series Prediction. Computer \& Industrial Engineering, v. 42, n. 2-4, p. 371-375, 2002. https://doi.org/10.1016/S03608352(02)00036-0

INSTITUTO BRASILEIRO DE GEOGRAFIA E ESTATÍSTICA (IBGE). Censo Demográfico de 2010. IBGE, 2010. Disponível em: <http://cidades.ibge.gov.br/xtras/home.php>. Acesso em: 10 mar. 2017.

INTERGOVERNMENTAL PANEL ON CLIMATE CHANGE (IPCC). Intergovernmental Panel on Climate Change 2014: Summary for Policymakers. In: FIELD, C. B. et al. (orgs.). Climate Change 2014: Impacts, Adaptation, and Vulnerability. Cambridge: Cambridge University Press, 2014. p. 1-32, 2014. Disponível em: <www.ipccwg2.gov/AR5/images/uploads/ WG2AR5_SPM_FINAL.pdf>. Acesso em: 10 jun. 2017. 
KHANDELWAL, I. R. A. \& VERMA, G. Time Series Forecasting using Hybrid ARIMA and ANN Models based on DWT Decomposition. In: INTERNATIONAL CONFERENCE ON INTELLIGENT COMPUTING, COMMUNICATION \& CONVERGENCE, 2015, Índia. Procedia Computer Science, v. 48, p. 173-179, 2015.

LAGARIS, I. E.; LIKAS, A.; FOTIADIS, D. I. Artificial Neural Network for Solving Ordinary and Partial Differential Equations. IEEE Transactions on Neural Network, v. 9, n. 5, p. 987-1000, 1998. https://doi.org/10.1109/72.712178

LIRA, F. \& CARDOSO, A. Estudo de tendência de vazões de rios das principais bacias hidrográficas brasileiras. Revista Brasileira De Ciências Ambientais, n. 48, p. 21-37, 2018. https://doi.org/10.5327/Z2176-947820180273

LÚCIO, P.S.; SILVA, F.D.S.; FORTES, L.T.G.; SANTOS, L.A.R.; FERREIRA, D.B.; SALVADOR, M.A.; BALBINO, H.T.; SARMANHO, G.F.; SANTOS, L.S.F.C.; LUCAS, E.W.M.; BARBOSA, T.F.; DIAS, P.L.S. Um Modelo Estocástico Combinado de Previsão Sazonal Para a Precipitação no Brasil. Revista Brasileira de Meteorologia, v. 25, n. 1, p. 70-87, 2010. http://dx.doi. org/10.1590/S0102-77862010000100007

MARENGO, J. A.; TOMASELLA, J.; NOBRE, C. A. Mudanças climáticas e recursos hídricos. In: BICUDO, C. E. M.; TUNDISI, J. G.; SCHEUENSTUHL, M. C. B. (orgs.). Águas do Brasil: análises estratégicas. São Paulo: Instituto de Botânica, 2010. 224 p. cap. 12. Disponível em <http://abc.org.br/IMG/pdf/doc-818.pdf>. Acesso em: 10 jun. 2017.

MORETTIN, P. A. \& TOLOI, C. M. C. Análise de Séries Temporais. 2. ed. São Paulo: Edgard Blucher, 2006.

NUNES, L. N.; KLÜCK, M. M.; FACHEL, M. G. Uso da imputação múltipla de dados faltantes: uma simulação utilizando dados epidemiológicos. Cadernos Saúde Pública, Rio de Janeiro, v. 25, n. 2, p. 268-278, 2009.

SAFEE, S. \& AHMAD, S. Comparing the Univariate Modeling Techniques, Box-Jenkins and Artificial Neural Network (ANN) for Measuring of Climate Index. Applied Mathematical Sciences, v. 8, n. 32, p. 1557-1568, 2014. http://dx.doi. org/10.12988/ams.2014.4150

SILVEIRA, C.; SOUZA FILHO, F.; VASCONCELOS JUNIOR, F.; ARAÚJO JUNIOR, L.; CABRAL, S. Mudanças climáticas e o setor hidroelétrico brasileiro: uma análise com base em modelos do IPCC-AR5. Revista Brasileira de Ciências Ambientais, n. 47, p. 46-60, 2018. https://doi.org/10.5327/Z2176-947820180210

SMITH, L. An introduction to neural network. 1996. Disponível em: <http://www.cs.stir.ac.uk/ Iss/NNIntro/InvSlides. html>. Acesso em: 10 jun. 2017.

TEALAB, A.; HEFNY, H.; BADR, A. Forecasting of Nonlinear Time Series Using ANN. Future Computing an Informatics, v. 2, n. 1, p. 39-47, 2017. https://doi.org/10.1016/j.fcij.2017.05.001

THE R PROJECT FOR STATISTICAL COMPUTING. Disponível em: <http://www.r-project.org>. Acesso em: 10 jan. 2017.

ZHANG, G. P. Time Series Forecasting Using a Hybrid ARIMA and Neural Network Model. Neurocomputing, v. 50, p. 159-175, 2003. https://doi.org/10.1016/S0925-2312(01)00702-0 